\title{
Praksis Orangtua Dalam Mendidik Anak Menurut Amsal 22 : 6 Terhadap Perilaku Sosial - Ekspresif Siswa
}

\author{
Oyen Marpaung, ${ }^{1}$. Desetina Harefa, ${ }^{2}$ Imayanti Nainggolan ${ }^{3}$ Ardianto Lahagu ${ }^{4}$ \\ Prodi PAK, STT Real Batam \\ Prodi PAK, STT Real Batam \\ Prodi PAK, STT Real Batam \\ Prodi PAK, STT Real Batam \\ oyen_marpaung@yahoo.com
}

\begin{abstract}
Parents have an important role in every aspect of children's lives with social behavior. Socialexpressive behavior of a person can determine the merits of a society's assessment of that person. If someone has a good social-expressive behavior, then society will judge that person as a person of good character, and vice versa. God gives instructions to parents to educate their children in Proverbs 22: 6. The role of parents in educating children is contained in the commands according to Proverbs 22: 6, namely maintaining, training, guiding or guiding, and leading; with the aim that children become successful people in their lives, and not deviate from the path of parental education, as written in Proverbs 22: 6, which is the right path according to God's Word. Nondeviant behavior can be seen from how children love God, love themselves, love others, and also love the environment. Social-expressive behaviors, among others, are competitive and noncompetitive, aggressive and non-aggressive, calm or calm and socially uneasy, as well as showing off or showing themselves and not showing themselves. From the role of parents in educating children, children are expected to be able to establish good social relationships with others, be able to control themselves, and be able to be mature.
\end{abstract}

Keywords: Education, parents, social behavior, expressive, children.

\begin{abstract}
Abstrak
Orang tua memiliki peranan penting dalam setiap aspek kehidupan anak dengan perilaku sosialnya. Perilaku sosial-ekspresif seseorang dapat menentukan baik buruknya penilaian masyarakat terhadap diri orang tersebut. Jika seseorang memiliki perilaku sosial-ekspresif yang baik, maka masyarakat akan menilai orang tersebut sebagai orang yang sifatnya baik, begitu juga sebaliknya. Allah memberikan perintah kepada para orang tua untuk mendidik anaknya dalam Amsal 22:6. Peranan orang tua dalam mendidik anak tertuang dalam perintah menurut Amsal 22:6, yaitu memelihara, melatih, menuntun atau membimbing, dan memimpin; dengan tujuan supaya anak menjadi orang yang berhasil dalam hidupnya, dan tidak menyimpang dari jalan didikan orang tua, seperti yang tertulis dalam Amsal 22:6, yaitu jalan yang benar sesuai dengan Firman Tuhan. Perilaku tidak menyimpang dapat dilihat dari bagaimana anak mengasihi Tuhan, mengasihi diri sendiri, mengasihi sesama, dan juga mencintai alam lingkungan. Perilaku sosial-ekspresif yaitu di antaranya adalah sifat suka bersaing dan tidak suka bersaing, sifat agresif dan tidak agresif, sifat kalem atau tenang dan tidak tenang secara sosial, serta sifat suka pamer atau menonjolkan diri dan tidak menonjolkan diri. Dari peranan orang tua dalam mendidik anak, diharapkan anak mampu menjalin hubungan sosial yang baik dengan orang lain, mampu mengendalikan diri, serta mampu bersikap dewasa. Kata Kunci: Didikan, orangtua, Perilaku sosial, ekspresif, Anak.
\end{abstract}




\section{PENDAHULUAN}

Dalam memasuki zaman millennium sekarang ini, manusia dihadapkan pada tuntutan supaya mampu menghadapi persaingan bebas yang menuntut manusia-manusia unggul agar mampu menghadapinya. Maka Untuk menghadapinya, manusia membutuhkan para generasi-generasi penerus yang memiliki kompeten, yang mampu bersosialisasi secara baik dan berkepribadian yang utuh. Memiliki kemampuan berperilaku sosial harus dimiliki sejak anak masih kecil sebagai suatu dasar bagi perkembangan anak dalam lingkungan yang luas. Jika anak tidak memiliki ketidak mampuan dalam dirinya yang diharapkan dilingkungannya ,maka anak tersebut akan terkucil dari dari tempat lingkungannya,sehingga anak kurang percaya diri pada diri sendiri. Maka akibatnya anak anak akan mengalami hambatan dalam masa pertumbuhannya dimasa kanak-kanaknya. Pada umumnya anak yang usianya 6-12 tahun memiliki kemauan yang kuat untuk dapat diterima dikelompoknya. Anak akan terus menerus untuk berusaha untuk dapat bergabung dan diterima disekelompoknya. Jika anak itu tidak diakui dikelompoknya,anak tersebut akan berusaha supaya sampai diterima dikelompoknya. Anak yang memiliki keinginan yang kuat dapat menuntut sejumlah kemampuan sosial yang dimilikinya. Anak tidak semua mampu menerapkan perilaku sosial seperti yang orang tua harapkan dan anak tidak semua mampu menerapkan perilaku sosial yang kita harapkan dalam kelompoknya. Beberapa anak ada yang memiliki sikap membangkang, tidak mau kalah atau ingin selalu menang sendiri, tidak mau berbagi dengan teman lain, suka pamer dan sebagainya. Maka Untuk dapat membantu mengatasi ketidakmampuan anak berperilaku sosial yang baik dalam menyiapkan anak memasuki lingkungan pergaulan yang lebih luas, maka sangat dibutuhkan layanan bimbingan sosial. Jika anak memiliki perilaku sosial-ekspresif yang kurang baik, maka masyarakat juga akan menilai anak tersebut sebagai anak yang memiliki sifat buruk. Ketika seseorang sudah dinilai buruk oleh masyarakat, maka pada umumnya masyarakat akan cenderung menghindari orang tersebut. Ketiga,karena peranan orang tua sangat memberikan pengaruh yang positif terhadap perilaku sosial-ekspresif anak. Anak yang selalu diperhatikan, dididik, dan diarahkan dengan baik oleh orangtuanya pada umumnya akan tumbuh menjadi anak yang baik dalam berpikir, bersikap, dan memiliki berperilaku sosial di lingkungan masyarakat.

Masalah yang kerap terjadi adalah bahwa peserta didik tidak memiliki hubungan sosial yang baik dengan peserta didik yang lain. Peserta didik memiliki sikap yang kurang sopan dan sering tidak menghormati guru ketika sedang mengajar. Ketika guru mengajar di kelas 5, tiba-tiba ada salah satu peserta didik kelas 6 yang masuk kelas dan tanpa rasa bersalah untuk meminta sesuatu alat belajar terhadap siswa kelas 5. Sementara Fredy Simanjuntak memaparkan epidemi social yang telah mengambil banyak korban pada anak- 
anak, baik tua dan muda. Wujudnya sering terlihat dalam bentuk masalah emosional, sosial, spiritual, akademik, fisik, kriminal, dan bunuh diri di kemudian hari dalam hidup. ${ }^{1}$

Ada beberapa indikasi bahwa sosok peranan mendidik utama ini kurang berfungsi bagi anak-anaknya. Orangtua banyak yang sibuk bekerja dan karena kesibukan tersebut, sehingga waktu yang tersedia untuk kebersamaan dengan anak-anaknya relatif menjadi sedikit, sehingga dengan minimnya waktu yang sedikit orangtua kurang menegetahui perkembangan penegetahuan dan perilaku sosial anak. Orangtua masih sering memiliki tanggapan dan memperlakukan anaknya sama seperti anak orang lain yang kurang memahami perilaku sosial sehingga anaknya kurangnya bersosialisasi dilingkungan masyarakat dan sekolah. Situasi dan kondisi yang seperti ini akan dapat menjadi pemicu beralihnya sosok orangtua sebagai teladan kepada sosok diluar orangtuanya sendiri, meskipun sebenarnya didalam Firman Tuhan jelas mengingatkan tentang keluarga Kristen bahwa dalam hal ini orangtua agar harus melaksanakan tanggungjawabnya untuk mendidik anak-anaknya, Ulangan 6: 7-9 dan Amsal 29:17, Efesus 6:1-4. ${ }^{2}$

Keterbatasan peranan orang tua dalam mendidik anaknya dapat menimbulkan terjadinya sebuah pertengkaran disekolah karena anak merasa paling hebat disekolah sehingga anak tersebut tidak suka bersosialisasi dikelas dan tidak menghargai guru dan teman-temannya,oleh karena itulah peranan sebagai orangtua dalam mendidik anak sangat diperlukan pada usia dini berdasarkan Amsal 22:6 agar perilaku sosial anak dapat dibentuk dari usia mudanya sehingga dimasa tuanya pun anak tersebut tidak menyimpang dari ajaran Firman Tuhan.

\section{METODE}

Penelitian ini menggunakan jenis penelitian kualitatif, yaitu suatu metode penelitian yang digunakan untuk meneliti pada kondisi objek yang alamiah, dimana peneliti adalah sebagai instrumen kunci. Penelitian kualitatif adalah penelitian yang menghasilkan data deskriptif berupa kata-kata tertulis atau lisan dari orang-orang dan perilaku yang dapat diamati.

\section{HASIL DAN PEMBAHASAN}

Analisis Teks Amsal 22 : 6

"Didiklah orang muda menurut jalan yang patut baginya, maka pada masa tuanyapun ia tidak akan menyimpang dari pada jalan itu." (Amsal 22:6 ). "Train up a child in the way he should go: and when he is old, he will not depart from it." (Proverb 22:6 KJV).

Sifat-sifat baik yang tertanam dalam diri anak akan melekat seumur hidupnya. Biasanya, pada bejana akan tertinggal aroma zat dari bumbu yang pertama kali dimasukkan

\footnotetext{
${ }^{1}$ Fredy Simanjuntak, "Problematika Disorganisasi Dan Disharmonisasi Keluarga," in Keluarga Yang Misioner, 2018.

${ }^{2}$ Dr. Daniel Nuhamara, "Pembimbing Pendidikan Agama Kristen,” in Jurnal Info Media, 2007.
} 
ke dalamnya. Banyak orang sungguh telah menyimpang dari jalan baik yang diajarkan kepada mereka. Salomo sendiri melakukannya. Namun pengajaran di masa muda bisa menjadi sarana bagi mereka untuk memulihkan diri, seperti yang diperkirakan terjadi pada Salomo. Setidaknya, orangtua akan terhibur karena telah menunaikan tugas mereka dan telah menggunakan sarana tersebut. ${ }^{3}$

\section{Didiklah}

Dalam bahasa Ibrani kata mendidik berasal dari kata "_ _" "chenokh". Ayat ini menunjukkan hubungan yang paralel, "dilukiskan sebagai seorang pengasuh yang memberi makan anak asuhannya untuk mendapatkan didikan lebih lanjut." Memberi makan disini bukanlah makanan jasmani melainkan makanan rohani. Makanan rohani ialah firman Tuhan. Paulus menggambarkan firman Tuhan itu sebagai air susu murni yang dapat memberikan pertumbuhan rohani dalam kehidupan manusia (2 Petrus 2:2).

Kata "didiklah" ini berasal dari bahasa Yunani yang berarti mengabdikan. "Orang bijaksana dalam hal ini adalah orang tua diminta untuk mengabdikan dirinya bagi anakanaknya dengan mendorong anak-anak mencari Allah sehingga mereka menemukan pengalaman spiritual dengan Allah dan dapat menikmati pengalaman itu yang tidak mereka lupakan" Jadi kata "didiklah" atau "mendidik" menunjuk kepada hubungan paralel antara orang tua dan anak-anak atau pengasuh dan anak-anak asuhannya, di mana orang tua mengabdikan dirinya untuk melatih (trainup) dengan disiplin kepada anak-anaknya, supaya mereka membaktikan diri kepada Allah sang pencipta, sumber hikmat dan kehidupan.

Lawrence Richards dalam bukunya Pelayanan Kepada Anak-Anak mengatakan bahwa sasaran dari membesarkan anak menurut Kitab Amsal secara spesifik adalah membimbing generasi baru untuk memilih jalan hikmat atau jalan bermoral di mana orang muda tersebut akan mengimplikasikan pilihan pribadinya untuk hidup kudus. "Kekudusan yang dimaksudkan adalah melakukan apa yang baik dan mengikuti jalan yang sudah ditentukan dengan jelas di dalam hukum Taurat ${ }^{6} . "$

\section{Orang Muda}

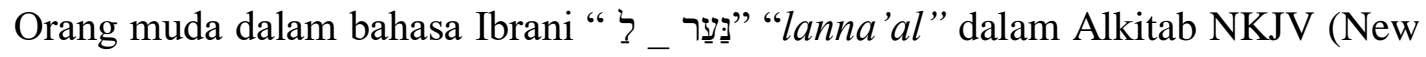
King James Version) diterjemahkan dengan kata " $a$ boy"7 Yang berarti "anak laki-laki; putra". Sedangkan KJV dan NIV menyebutkan sebagai "a child" yang berarti seorang anak, sama artinya dengan terjemahan Bode "seorang budak". Menurut Mery Go

\footnotetext{
${ }^{3}$ Matthew Henry, Tafsiran Alkitab, n.d.

4 "Mendidik Anak," in Renungan Perspektif, 2009.

5 Alkitab Penuntun (Malang: Gandum Mas dan Lembaga Alkitab Indonesia, 2000).994

${ }^{6}$ Lawrence O. Richard, Pelayanan Kepada Anak-Anak (Bandung: Yayasan Kalam Hidup, 2007).29-30

${ }^{7}$ Jay P. Green, The Interlinier Bible Hebrew/English (Michigan: Baker Book House, n.d.). 1566

${ }^{8}$ Peter Salim, Advanced English-Indonesia Dictionary (Jakarta, 1989). 101
} 
Setiawani, "orang muda yang dimaksudkan dalam ayat ini mencakup anak-anak, remaja dan pemuda". Jadi "orang muda" yang dimaksud di sini adalah seorang anak atau usia muda. Dimana sebagai orang tua dan pelayan anak-anak memberikan suatu pendidikan sejak anak - anak kecil sehingga di masa yang akan datang atau masa tuanya ia tetap kuat berdiri dalam imannya, tidak menyimpang dari jalan Tuhan. Penulis Amsal menganjurkan agar pada saat usia anak masih kecil, sedini mungkin diberikan pendidikan yang benar dan di masa kecil pastilah ia tak akan mudah terombang ambing oleh ajaran dan kenikmatan dunia.

\section{Menurut Jalan yang Patut Baginya}

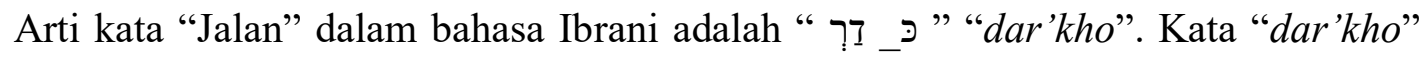
berasal dari kata dasar "derekh", yang berarti "jalan". Kata "dar'kho" merupakan kata kerja bentuk infinitive keterangan, dengan akhiran ganti " $o$ ", yang berarti "-nya". kata "dar'kho" berarti "jalannya". Dalam KJV berarti "his way" dan dalam bahasa Indonesia "his" berarti "- nya" dan "way" berarti "jalan", jadi "his way" berarti "jalannya". Secara harfiah kata "jalan" berarti "kecenderungan, dan mengacu pada suatu rancangan atau suatu arahan internal., 10

Di dalam Buku Ensiklopedia Fakta Alkitab dimana kata "Jalan" itu“mengajar anakanak untuk menghormati ibu bapa dan orang-orang tua" ${ }^{11}$.

Kata "Jalan" ialah jalan yang tepat dalam terang penyataan Allah. Selain itu kata "jalan" juga berarti kehendak/keinginan Tuhan / Firman Tuhan atau bisa juga secara harafiahnya yaitu hal-hal yang bersifat baik menurut kehendak Tuhan. Oleh karena itu pengajaran diatas mengandung arti agar orangtua mengajarkan seorang anak untuk menjauhkan diri dari perbuatan dosa yang tidak sesuai dengan kehendak Tuhan. Pengajaran rohani inilah yang bertujuan agar anak-anak di usia muda akan memahami firman Tuhan didalam segala aspek kehidupannya sehingga mereka akan dewasa dalam Kristus Yesus. Sebagaimana yang dikatakan oleh Calvin Melar, "Pengajaran firman Tuhan yang sangat teratur dari setiap ibadah adalah sangat penting bagi pertumbuhan dan pendewasaan keKristenan ${ }^{12} . "$

Charles F. Boyd mengatakan dalam bukunya, "Menyikapi perilaku anak sesuai dengan karakternya" bahwa kata "jalan" berasal dari kata Ibrani "Derek" yang berarti kecenderungan. Oleh karena itu, terjemahan yang lebih tepat menurutnya ialah "Sesuaikanlah pendidikan anak anda dengan umurnya sehingga sejalan dengan rancangan

\footnotetext{
${ }^{9}$ Mery Go Setiawani, Pembaruan Mengajar (Bandung: Yayasan Kalam Hidup, 1999). 13

${ }^{10}$ Charles F. Boyd, Menyikapi Perilaku Anak Sesuai Dengan Karakternya (Bandung: Yayasan Kalam Hidup, 2006). 19

${ }^{11}$ J. L. Packer, Ensiklopedia Fakta Alkitab 2 (Jakarta: Gandum Mas, 2001). 927

${ }^{12}$ Calvin Miler, Pola Hidup Orang Kristen (Bandung: Yayasan Kalam Hidup, 1990).58
} 
alamiahnya, maka ketika ia menjadi dewasa, ia tidak akan menyimpang dari pola hidupnya ${ }^{13}$."

J. Vernon McGee menjelaskan ayat dari Amsal 22: 6 sebagai berikut, "We are to train up a child concerning the way he should go. What he is saying is that God has a way He wants him to go, and parents are to find out that way. They are not to bring up a child in the way they think he should go but in the way God wants him to go."14 (Kita melatih seorang anak menurut jalan yang seharusnya dia tempuh).

\section{Masa Tuanyapun Ia Tidak Akan Menyimpang dari Jalan Itu}

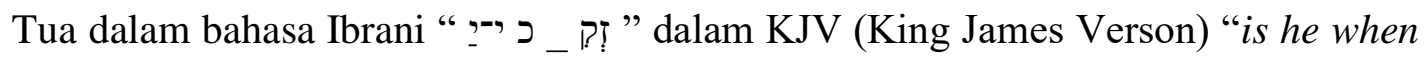
old" yang berarti "dia ketika tua". "Masa tua ialah orang yang tertua atau yang paling berpengaruh di antara sesuatu suku bangsa, disebut tua-tua. ${ }^{15}$ " Dalam kamus Bahasa Indonesia "masa tua" yang berarti "sudah lama hidup, lanjut usia (tidak muda lagi). ${ }^{16 "}$ Jadi di masa tua berarti sudah lanjut umur atau umur yang sudah panjang dan sudah banyak memiliki pengalaman hidup. Musa mengatakan bahwa masa tua itu berumur tujuh puluh sampai delapan puluh tahun (Mazmur 90:10).

\section{Perilaku sosial ekpresif menurut Amsal 22:6}

\section{Ketaatan dan Tanggung Jawab}

Musa adalah seorang anak di lahirkan dari keluarga Lewi, namun dibesarkan oleh putri Firaun yang mengangkat dia sebagai anaknya (Keluaran 2:6). Meskipun Musa dididik selama 40 tahun dalam pengetahuan orang Mesir namun dia tetap mengingat dirinya sebagai orang Ibrani karena sejak bayi hingga lepas susu atau masa kanak-kanak, orang tuanyalah yang mengasuh atau mendidik dia (Keluaran 2:9-11). Musa juga mengalami pembentukan oleh Tuhan selama 40 tahun di padang gurun dan Allah memanggil dia menjadi pemimpin besar bangsa Israel sepanjang sejarah (Keluaran 2:21-3:10). Tuhan telah memiliki rancangan terbaik bagi Musa untuk dijalaninya menurut jalan yang patut baginya. Musa memilih untuk sengsara mengikuti Tuhan daripada tetap tinggal di istana orang kafir sebagaimana yang dikatakan dalam Ibrani 11:22-29. Dari kehidupan musa ini orangtua harus bisa mendidik dan mengajarkan anak tentang ketaatan dimasa mudanya, taat dalam melaksanakan tugas dan tanggungjawabnya sebagai anak.

\section{Kedisiplinan, kesetiaan dan kerjasama.}

Daniel adalah seorang pemuda Israel berasal dari Yehuda yang diambil pada tahun pemerintahan Yoyakim, raja yang dikalahkan oleh Nebukadnezar. "Daniel diambil dari tanah airnya bersama dengan Hanaya, Misael, dan Azarya. Mereka didik didalam

\footnotetext{
${ }^{13}$ Boyd, Menyikapi Perilaku Anak Sesuai Dengan Karakternya.

${ }^{14}$ J. Vernon McGee, Thru The Bible Vol 3 (Nashville TN: Thomas Nelson Inc, 1982).76

15 "Http://Alkitab.Sabda.Org/Dictionary.Php?Word=Tua-Tua," Desember 2019.

${ }^{16}$ Hasan Alwi, Kamus Besar Bahasa Indonesia (Jakarta: Balai Pustaka, 2005).
} 
istana. Daniel adalah seorang bangsawan namun di posisi pemerintahan ia sangat tinggi ${ }^{17}$." Sebagaimana kita ketahui bahwa ia adalah seorang yang takut akan Tuhan. Dia tidak memilih makan santapan raja yang menajiskan dan berhala. "Sebagaimana diketahui bahwa Daniel tidak mencari hormat dan tidak berani mengambil dan melakukan keputusan. Daniel juga adalah orang yang penting dalam pemerintahan Nebukadnezar." Ia juga di kenal sebagai seorang yang berpengetahuan (Daniel 1:4, 17-20). Dan ia juga adalah satu pemimpin dalam pemerintahan kerajaan Babel dan Media-Persia. "Ia (Daniel) memiliki hikmat dan pengetahuan, dan kepandaian (Daniel 2:48, 5:29, 6:29) ${ }^{18}$." Daniel adalah satu dari antara pemuda Yahudi yang pintar. Jangan heran "Daniel sangat trampil saat bertugas melayani raja. Percaya dirinya membuatnya sanggup berhadapan dengan raja ${ }^{19}$." Dari kehidupan Daniel ini penulis menyarankan terhadap orangtua apabila orangtua mengajarkan dan menerapkan terhadap anak tentang kehidupan Daniel,dimana dalam kehidupan Daniel adalah seorang yang taat dan displin tentang apa yang tuhan perintahkan Kepada nya, demikian juga orangtua jika hal ini diterapkan terhadap anak dimasa mudanya maka anak tersebut akan disiplin dan setia selama masa hidupnya seperti kehidupan Daniel.

\section{KESIMPULAN}

Praksis orang tua dalam mendidik anak menurut Amsal 22:6 memiliki pengaruh yang sangat kuat dengan perilaku sosial ekspresif anak dimana jika orang tua berperan aktif dalam mendidik anak serta membawa pengajaran menurut Amsal 22:6 dalam kehidupan sehari-hari anak akan mampu mengendalikan diri (menahan diri dari emosi, tindakan, dan pikiran yang menyimpang atau yang tidak penting), anak mampu bersikap dewasa, mampu menjalin hubungan sosial yang baik dengan orang lain seperti hubungan antar pribadi, hubungan pribadi dengan kelompok, dan hubungan antar kelompok. Mengingat bahwa mendidik adalah merupakan salah satu keharusan dan tanggungjawab yang pertama orangtua terhadap anak maka sebaiknya orangtua terus belajar, merefleksi diri untuk melihat apakah dirinya telah menjadi teladan yang baik bagi anaknya dalam perkataan, sikap dan tingkah laku. Tidak mengeluarkan kata-kata yang kotor, tidak emosional ,membangun apalagi merendahkan kemampuan anak dan apakah orangtua sudah mendidik anak berdasarakan firman Tuhan dengan Benar.

\section{KEPUSTAKAAN}

Alwi, Hasan. Kamus Besar Bahasa Indonesia. Jakarta: Balai Pustaka, 2005.

Boyd, Charles F. Menyikapi Perilaku Anak Sesuai Dengan Karakternya. Bandung: Yayasan Kalam Hidup, 2006.

Green, Jay P. The Interlinier Bible Hebrew/English. Michigan: Baker Book House, n.d. Henry, Matthew. Tafsiran Alkitab, n.d.

McGee, J. Vernon. Thru The Bible Vol 3. Nashville TN: Thomas Nelson Inc, 1982.

\footnotetext{
17 “Http://Biografialkitab.Blogspot.Com/2009/09/Biografi-Singkat-Daniel.Html," Desember.

${ }^{18}$ Roswitha \& Julianto Simanjuntak, 9 Masalah Utama Remaja (Yayasan Konseling, 2010). 7

${ }^{19}$ Ibid. 3
} 
Miler, Calvin. Pola Hidup Orang Kristen. Bandung: Yayasan Kalam Hidup, 1990.

Nuhamara, Dr. Daniel. "Pembimbing Pendidikan Agama Kristen." In Jurnal Info Media, 2007.

Packer, J. L. Ensiklopedia Fakta Alkitab 2. Jakarta: Gandum Mas, 2001.

Richard, Lawrence O. Pelayanan Kepada Anak-Anak. Bandung: Yayasan Kalam Hidup, 2007.

Salim, Peter. Advanced English-Indonesia Dictionary. Jakarta, 1989.

Setiawani, Mery Go. Pembaruan Mengajar. Bandung: Yayasan Kalam Hidup, 1999.

Simanjuntak, Fredy. "Problematika Disorganisasi Dan Disharmonisasi Keluarga.” In Keluarga Yang Misioner, 2018.

Simanjuntak, Roswitha \& Julianto. 9 Masalah Utama Remaja. Yayasan Konseling, 2010. Alkitab Penuntun. Malang: Gandum Mas dan Lembaga Alkitab Indonesia, 2000.

"Http://Alkitab.Sabda.Org/Dictionary.Php?Word=Tua-Tua." Desember.

"Http://Biografialkitab.Blogspot.Com/2009/09/Biografi-Singkat-Daniel.Html." Desember.

“Mendidik Anak.” In Renungan Perspektif, 2009. 